\title{
Primary hepatocellular carcinoma associated with Wilson's disease in a young woman
}

\author{
R. Guan ${ }^{1}$, C.J. Oon ${ }^{1}$, P.K. Wong ${ }^{1}$, W.C. Foong ${ }^{2}$ and A. Wee ${ }^{3}$ \\ Departments of ${ }^{1}$ Medicine, ${ }^{2}$ Surgery and ${ }^{3}$ Pathology, National University of Singapore, Singapore General \\ Hospital, Singapore 0316.
}

\begin{abstract}
Summary: A 27 year old woman with hepato-lenticular degeneration (Wilson's disease) was found to have primary hepatocellular carcinoma (PHC) three and a half years after she was started on treatment with D-penicillamine. The tumour was resected since when she has remained well. Her liver function tests were normal throughout the course of her disease. The available literature is reviewed and possible mechanisms for this association proposed.
\end{abstract}

\section{Introduction}

Primary hepatocellular carcinoma (PHC) is rarely associated with Wilson's disease (Lygren, 1959; Girard et al., 1968; Kamakura et al., 1975; Terao et al., 1982; Wilkinson et al., 1983), although it is a common complication of long-standing cirrhosis especially associated with haemochromatosis and hepatitis B infection. In women of child bearing age PHC is rare; most tumours appear in older women (Oon et al., 1979) and even then, they are far outnumbered by men with this malignancy. We report the occurrence of PHC in a young woman with Wilson's disease who had never been on oral contraceptives or exposed to hepatitis $B$ virus.

\section{Case report}

A female Chinese, first presented in 1976 at the age of 21 with difficulty in writing and frequent falls from an unsteady gait. Later she developed muscular weakness and dysphagia to both solids and liquids. Examination then revealed diminished motor power with persistent effort and myasthenia gravis was suspected. Repeated tensilon tests however were negative. Her dysphagia improved somewhat with amitriptyline. She was seen two years later with choreo-athetosis and dystonia. Kayser-Fleischer rings and hepato-splenomegaly were then noted and Wilson's disease was confirmed by low serum caeruloplasmin oxidase activity to phenylenediamine hydrochloride on two occasions: $0.04 \mathrm{OD}$ and $0.02 \mathrm{OD}$ (normal $0.2-0.5 \mathrm{OD}$ ), low serum copper

R. Guan, M.R.C.P.; C.J. Oon, M.D., M.R.C.P.; P.K. Wong, F.R.C.P.; W.C. Foong, F.R.C.S.; A. Wee, M.R.C.Path. Accepted: 21 June 1984 level of $6.4 \mu \mathrm{mol} / 1(40 \mu \mathrm{g} / \mathrm{dl})$ (normal $12-26 \mu \mathrm{mol} / 1$ or $75-160 \mu \mathrm{g} / \mathrm{dl}$ ), and a raised $24 \mathrm{~h}$ urinary copper excretion of $1.92 \mu \mathrm{mol}(120 \mu \mathrm{g})$ increasing to $9.6 \mu \mathrm{mol}$, $(600 \mu \mathrm{g})$ after D-penicillamine (normal $0.1-0.4 \mu \mathrm{mol}$ or $5-25 \mu \mathrm{g}$ per $24 \mathrm{~h}$ ). Her liver function tests were normal. Family history and screening revealed no other siblings affected with Wilson's disease or liver problems. She was started on D-pencillamine and made a slow recovery of her central nervous system signs although dystonia was still present after 3 years of therapy (750-1000 mg D-penicillamine daily). Her liver function tests remained normal during this period.

In 1981, at the age of 27 , she presented with a six week history of epigastric pain which was referred to the left shoulder. She did not drink and had never been on any hormonal contraceptive. A hard, nodular left lobe of the liver was felt with its edge $12 \mathrm{~cm}$ from the xiphisternum. The spleen was just palpable.

Investigations showed normal serum transaminases, bilirubin and alkaline phosphatase. Hepatitis B surface antigen (HBsAg) (EIA), anti-HBs antibody (RIA), and anti-HBc antibodies (RIA) were all absent. $\alpha$-feto protein was positive at $27,000 \mathrm{ng} / \mathrm{dl}$ (RIA). Colloid indium liver scan showed an enlarged liver with no uptake in the left lobe. A selective hepatic angiography suggested deviation of the aorta to the right by a vascular tumour which has replaced the left lobe of the liver. This appeared resectable. There were calcified shadows just below the left hemidiaphragm which was thought to be due to tumour calcification (Figure 1).

At operation, a large PHC involving the left lobe of the liver was found. There was also macronodular cirrhosis. The common bile duct contained a solitary

The Fellowship of Postgraduate Medicine, 1985 


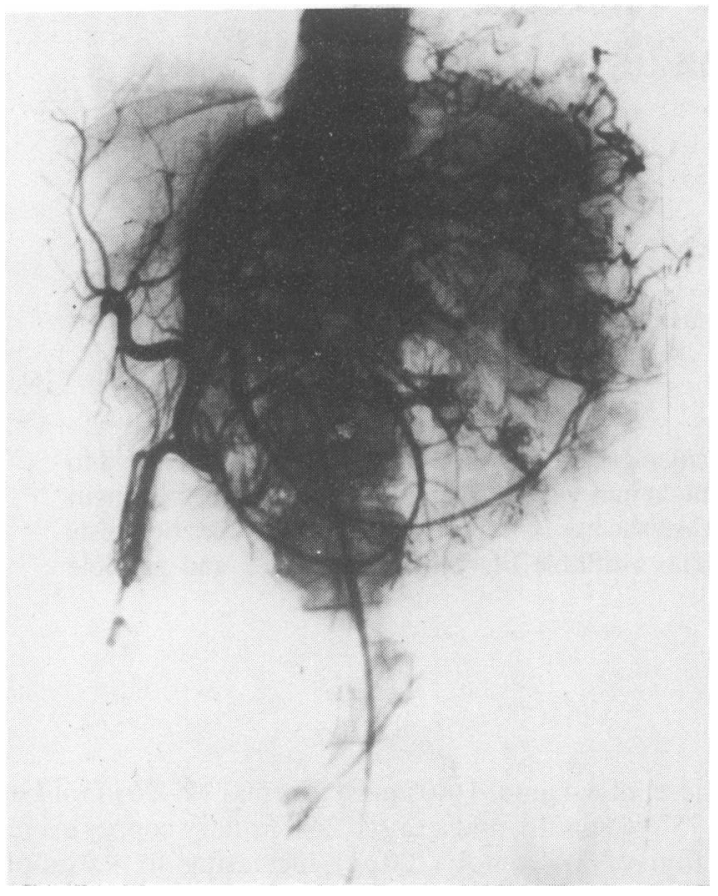

Figure 1 Hepatic angiogram showing huge tumour mass replacing the left lobe of the liver.

stone and the spleen was enlarged. A left partial hepatectomy was performed. The tumour measured $18 \mathrm{~cm} \times 13 \mathrm{~cm}$ in diameter with central necrosis. Histology showed hepatocellular carcinoma with trabecular pattern, and focal pleomorphism (Figure 2). The unaffected liver section showed macronodular cirrhosis and hepatocellular copper deposits were demonstrated by rubeanic acid staining. Hepatic

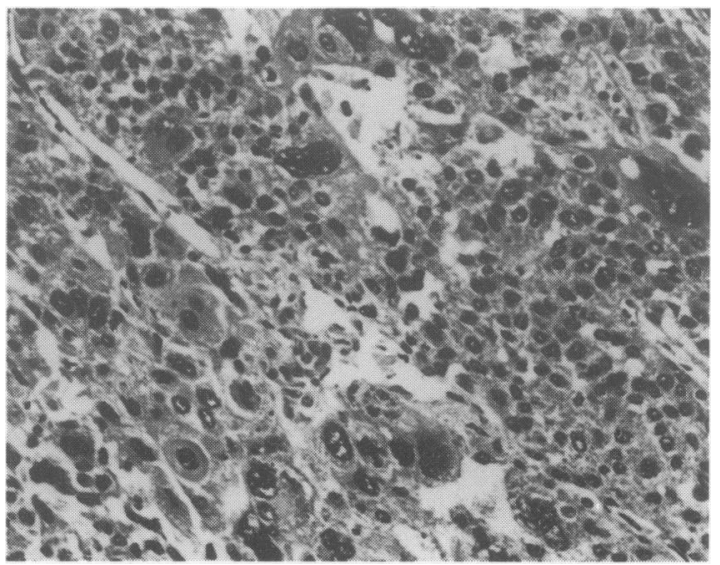

Figure 2 Hepatocellular carcinoma showing cellular pleomorphism. (H \& E, × 250). copper concentration measured by atomic absorption spectrophotometry was $104 \mu \mathrm{g} / \mathrm{g}$ dry weight (normal $<55 \mu \mathrm{g} / \mathrm{g}$ dry weight). Her post-operative recovery was uneventful and she has had no recurrence of her $\varrho$ hepatoma to date.

\section{Discussion}

Wilson's disease is a rare, hereditary disorder of $\frac{\bar{c}}{\bar{c}}$ copper metabolism and homeostasis. Impaired $\widehat{\nabla}$ lysosomal copper excretion into the bile leads to copper accumulation in the body (Sternlieb et al., क 1973), starting in the liver which initially displays an $\vec{\circ}$ astonishing capacity to bind this metal (up to fifty $\overrightarrow{\vec{\omega}}$ times or more the normal concentration). No overt $\stackrel{\omega}{\sigma}$ disease is seen at this stage. The binding capacity of the $\bar{D}$ liver eventually becomes exceeded and copper induced 3 liver damage occurs as the metal is released into the circulation and gets deposited in other tissues like the $\overrightarrow{-}$ brain, kidneys and eyes. At the time of diagnosis, liver $\vec{A}$ cirrhosis is usually well established (Deiss \& Cartwright, 1971).

Only 5 cases of PHC associated with Wilson's 음 disease have been reported and all of them were males from 16 to 41 years old. Lygren (1959) suggested that $>$ malignant hepatoma in Wilson's disease was probably secondary to cirrhosis when he described a 16 year old $\overrightarrow{0}$ boy who died of PHC. Girard's patient (1968) was a 49 year old farmer who presented at 19 years of age wit neurological signs. Wilson's disease was diagnose three years afterwards but he was not treated with penicillamine till 17 years later at the age of 36 . Histology revealed a trabecular type of PHC with $\circ$ biliary secretion in some areas. Macronodular cirr- $\cong$ hosis was also present. Kamakura and co-workers $\overrightarrow{\overrightarrow{0}}$ (1975) described a 32 year old man with Wilson's 3 disease who was started on D-penicillamine only 18 局 months before his death from a massive intraperitoneal haemorrhage. He presented with neurological $\bar{D}$ signs 5 years before treatment was instituted. The fourth patient was a 40 year old Japanese (Terao et al., $\frac{0}{3}$ 1982) who presented with tremors and slurring of speech 6 years before he was diagnosed and started on $\frac{\mathrm{O}}{3}$ penicillamine and BAL. He died 11 years later. A 31

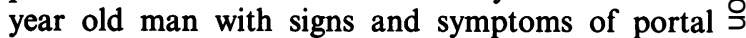
hypertension and liver insufficiency was reported by $\frac{D}{O}$ Wilkinson and fellow workers recently (1983). He was started on D-penicillamine 4 years after initial presen- $\tilde{O}$ tation but died 9 years later from liver failure. Hepatocellular carcinoma was diagnosed at necropsy. O

Edmonson \& Stainser (1954) suggested that the $\omega$ development of PHC is proportional to the length of morbidity in cases of cirrhosis. Patients with Wilson's $\bullet$ disease tend to survive longer since the advent of early $\Phi$ diagnosis and treatment with penicillamine. These long term survivors with cirrhosis may now present with PHC.

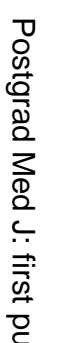


It has been shown experimentally that copper has an inhibitory effect on the factors responsible for PHC development in rats (Howell, 1958; Kammoto et al., 1973), although the level at which it is protective in man is unknown. This could be another explanation for the rarity of hepatoma in patients with Wilson's disease and other diseases with longstanding cirrhosis and accompanying marked copper retention, such as primary biliary cirrhosis (6 cases reported to date: Krasner et al., 1979; Mallett et al, 1981; Terris et al., 1982) and sclerosing cholangitis (none as yet reported). All the 5 reported patients with hepatoma and Wilson's disease have been treated with D-penicillamine which removes copper by chelating the excess metal. Hence the possible mechanisms for the

\section{References}

DEISS, A. \& CARTWRIGHT, G.E. (1971). Long term therapy for Wilson's disease. Annals of Internal Medicine, 75, 57.

EDMONSON, H.A. \& STEINSER, P.E. (1954). Primary carcinoma of the liver. Cancer, 7, 462.

GIRARD, P.F., VACHON, A. \& TOMMASI, M. (1968). Degenerescence hepatolenticulaire et cancer primitit du foie. Lyon Médicale, 17, 1395.

HOWELL, J.S. (1958). The effect of copper acetate on pdimethylaminaazobenzene carcinogenesis in the rat. British Journal of Cancer, 2, 594.

KAMAKURA, K., KIMURA, S. \& IGARASHI, S. (1975). A case of Wilson's disease with hepatoma. Journal of the Japanese Society of Internal Medicine, 64, 232.

KAMAMOTO, Y., MAKIURA, S., SUGIHARA, S., HIASA, Y., ARAI, M. \& ITO, N. (1973). The effect of copper on DLethionine carcinogenesis in rats. Cancer Research, 33, 1129.

KRASNER, N., JOHNSON, P.J., PORTMAN, B., WATKINSON, G., MACSWEEN, R.N.M. \& WILLIAMS. R. (1979). Hepatocellular carcinoma in primary biliary cirrhosis: report of four cases. Gut, 20, 255.

LYGREN, T. (1959). Hepatocellular degeneration and juvenile cirrhosis in the same family. Lancet, ii, 275.

MALLET, L., PETITE, J.P., AMAT, D., BLOCH, F., JUILLET, Y., CAMILLERI, J.P. \& HOUSSET, E. (1981). Hepatocellular development of PHC in our patient are a combination of macronodular cirrhosis consequent upon metal irritation and damage, and the lowering of liver copper to a level below that which is protective in the prevention of tumour formation.

Three cases of PHC complicating Wilson's disease have been reported in the last 3 years compared to the same number over the previous 30 years. This could suggest an increasing incidence of this complication and seems to correspond with the increased usage of penicillamine for the above condition. The possible protective role of copper in PHC formation may be relevant to the use of penicillamine for its immunosuppresive and anti-collagen binding properties (Sherlock, 1981) in other chronic liver conditions.

carcinoma and primary biliary cirrhosis: report of one case. Gastroenterologie Clinique et Biologique, 5(4), 379.

OON, C.J., YO, S.L. \& CHAN, S.H. (1979). Hepatocellular carcinoma in a patient on oral contraception who has been exposed to hepatitis B virus. Lancet, ii, 94.

STERNLIEB, I., VAN DE HAMER, C.J.A., MORELL, A.G., GREGORIADIS, G. \& SCHEINBERG, I.H. (1973). Lysosomal defect of hepatic copper excretion in Wilson's disease. Gastroenterology, 64, 99.

SHERLOCK, S. (1981). Disease of the Liver and Biliary System. 6th Ed., Blackwell Scientific Publications, Oxford. p. 235.

TERAO, H., ITAKURA, H., NAKATA, K., KONO, K., MURO, T., FURUKAWA, R., KUSOMOTO, M., MUNEHISA, T., NAGATAKI, S., ISHII, N., KOJI, T. \& HIRAMA, M. (1982). An autopsy case of hepatocellular carcinoma in Wilson's disease. Acta Hepatologica Japonica, 23, 439.

TERRIS, G., DE LA LANDE, P. \& VAURY, P. (1982). Hepatocellular carcinoma and primary biliary cirrhosis: a new case. Gastroenterologie Clinique et Biologique, 6(6-7), 593.

WILKINSON, M.L., PORTMANN, B. \& WILLIAMS, R. (1983). Wilson's disease and hepatocellular carcinoma; possible protective role of copper. Gut, 24, 767. 